\title{
Epilepsy and Adult Neurogenesis
}

\author{
Sebastian Jessberger ${ }^{1}$ and Jack M. Parent ${ }^{2}$ \\ ${ }^{1}$ Brain Research Institute, University of Zurich, 8057 Zurich, Switzerland \\ ${ }^{2}$ Department of Neurology, University of Michigan Medical Center and VA Ann Arbor Healthcare System, \\ Ann Arbor, Michigan 48109 \\ Correspondence: jessberger@hifo.uzh.ch
}

\begin{abstract}
Seizure activity in the hippocampal region strongly affects stem cell-associated plasticity in the adult dentate gyrus. Here, we describe how seizures in rodent models of mesial temporal lobe epilepsy (mTLE) affect multiple steps in the developmental course from the dividing neural stem cell to the migrating and integrating newborn neuron. Furthermore, we discuss recent evidence indicating either that seizure-induced aberrant neurogenesis may contribute to the epileptic disease process or that altered neurogenesis after seizures may represent an attempt of the injured brain to repair itself. Last, we describe how dysfunction of adult neurogenesis caused by chronic seizures may play an important role in the cognitive comorbidities associated with mTLE.
\end{abstract}

$T_{\mathrm{i}}^{\mathrm{h}}$ he epilepsies are a diverse group of neurological disorders that share the central feature of spontaneous recurrent seizures. Some epilepsies result from inherited mutations in single or multiple genes, termed idiopathic or primary epilepsies, whereas symptomatic or secondary epilepsies develop as a consequence of acquired brain abnormalities, such as from tumor, trauma, stroke, infection, or developmental malformation. Of acquired epilepsies, mesial temporal lobe epilepsy (mTLE) is a particularly common and often intractable form. In addition to pharmacoresistant seizures, the syndrome of mTLE almost always involves impairments in cognitive function (Helmstaedter 2002; Elger et al. 2004; von Lehe et al. 2006) that may progress even with adequate seizure control (Blume 2006).

Seizure activity in mTLE subjects typically arises from the hippocampus or other mesial temporal lobe structures. Simple and complex partial seizures, the most common seizure types in this epilepsy syndrome, often become medically refractory and may respond only to surgical resection of the epileptogenic tissue. Patients usually also have secondarily generalized tonic-clonic seizures, although these are often controlled by anticonvulsants. Hippocampi in pharmacoresistant mTLE usually show substantial structural abnormalities that include pyramidal cell loss, astrogliosis, dentate granule cell axonal reorganization (mossy fiber sprouting), and dispersion of the granule cell layer (GCL) (Blumcke et al. 1999, 2012).

Humans with mTLE often have a history of an early "precipitating" insult, such as a prolonged or complicated febrile seizure, followed by a latent period and then the development of epilepsy in later childhood or adolescence.

Editors: Fred H. Gage, Gerd Kempermann, and Hongjun Song

Additional Perspectives on Neurogenesis available at www.cshperspectives.org

Copyright (C) 2015 Cold Spring Harbor Laboratory Press; all rights reserved; doi: 10.1101/cshperspect.a020677 Cite this article as Cold Spring Harb Perspect Biol 2015;7:a020677 
These historical findings have led to the development of what are currently the most common animal models, the status epilepticus (SE) models, used to study epileptogenic mechanisms in mTLE. In these models, a prolonged seizure induced by chemoconvulsant (typically kainic acid or pilocarpine) treatment or electrical stimulation leads to an initial brain injury, followed, after a latent period of days to weeks, by spontaneous recurrent seizures. These models recapitulate much of the pathology of human mTLE (reviewed in Buckmaster 2004). Experimental paradigms are necessary to investigate mechanisms underlying mTLE, as surgical specimens from mTLE cases are collected at late stages of the disease and, thus, are unlikely to reveal early features critical for the disease process. Studies of experimental mTLE indicate that excess neural activity in the course of seizures not only damages existing, mature structures of the hippocampal formation but also dramatically affects endogenous neural stem cells (NSCs) within the adult rodent dentate gyrus (Bengzon et al. 1997; Parent et al. 1997; Scott et al. 1998). In the following, we will discuss the consequences of seizure activity on proliferation of NSCs, maturation and integration of newborn neurons, and the functional relevance of seizure-induced neurogenesis.

\section{SEIZURE-INDUCED CELL PROLIFERATION}

Prolonged seizure activity leads, after a latent period of several days, to a dramatic increase in cell proliferation (Fig. 1) judged by Ki67 ex- pression or short-pulse bromodeoxyuridine (BrdU) labeling in the dentate gyrus (Parent et al. 1997; Gray and Sundstrom 1998; Jessberger et al. 2005) and rostral subventricular zone (SVZ) (Parent et al. 2002). In the dentate, the immediate proliferative response appears to be mediated by radial glia-like type-1 cells, whereas at the peak of cell proliferation increased activation of doublecortin (DCX)expressing neuroblasts occurs (Huttmann et al. 2003; Jessberger et al. 2005; Lugert et al. 2010). BrdU labeling before SE has shown that most of the proliferating cells that respond to seizure activity are mitotically active even before the insult (Parent et al. 1999, 2006a). The severity and duration of seizure activity does not seem to be a major factor as even single, seizurelike discharges induce cell proliferation (Bengzon et al. 1997). However, the survival of seizure-generated granule cells, at least in certain SE models, appears to decrease with increased seizure severity (Mohapel et al. 2004) — an effect that is potentially mediated by subsequent inflammation (Ekdahl et al. 2003). Cell proliferation returns to baseline levels approximately 3 to $4 \mathrm{wk}$ following the initial SE episode (Parent et al. 1997; Bonde et al. 2006). Recent evidence suggests that, at later stages following SE, the potential for adult neurogenesis might even be reduced (Hattiangady et al. 2004; Kralic et al. 2005). The reasons for reduced neurogenesis late after seizures might either be "exhaustion" of the NSC pool or alterations in the neurogenic niche preventing support and proper function of NSCs.

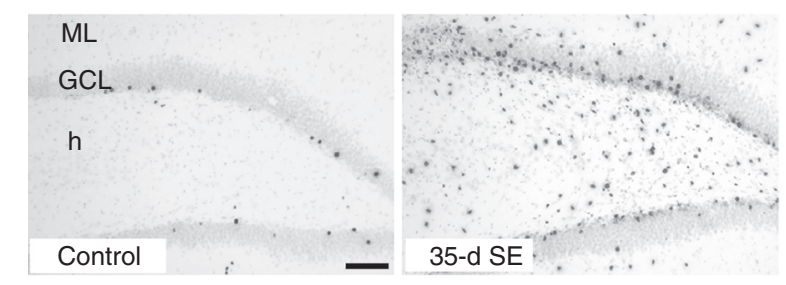

Figure 1. Pilocarpine-induced status epilepticus (SE) increases dentate gyrus cell proliferation. Dentate gyrus bromodeoxyuridine (BrdU) labeling in adult rats $35 \mathrm{~d}$ after pilocarpine-induced SE (right) or saline treatment in a control (left). BrdU immunoreactivity is increased markedly in the inner granule cell layer (GCL), hilus (h), and molecular layer $(\mathrm{ML})$ of the animal that experienced $2 \mathrm{~h}$ of continuous seizure activity (right). BrdU was given on days 7-21 after pilocarpine or saline treatment. Scale bar, $100 \mu \mathrm{m}$. 
A critical question that remains to be answered is how seizure activity translates into increased cell proliferation. It seems that NSCs are capable of "sensing" electrical activity (Deisseroth et al. 2004), and recent data suggest that many genes/pathways that regulate neurogenesis during embryonic development are also important in the context of adult NSC proliferation (Faigle and Song 2013). Direct mechanisms may involve signaling pathways, such as Notch, Sonic hedgehog, and Wnt signaling (Banerjee et al. 2005; Sibbe et al. 2012; Jang et al. 2013). Further, activation of glutamate and $\gamma$-aminobutyric acid (GABA) receptors expressed by dentate NSCs (Gould et al. 1994; Tozuka et al. 2005; Song et al. 2012) or changes in histone acetylation induced by seizures (Huang et al. 2002; Jessberger et al. 2007b) can alter dentate NSC proliferation in the adult. Alternatively, seizure-induced expression of trophic factors, such as brain-derived neurotrophic factor (BDNF), vascular endothelial growth factor (VEGF), and others by surrounding tissue, could indirectly induce NSC proliferation (Isackson et al. 1991; Gall 1993; Newton et al. 2003). A combination of mechanisms seems most probable, although defining them precisely is very challenging given the substantial alteration in gene expression that occurs following SE (Elliott and Lowenstein 2004).

\section{MATURATION AND INTEGRATION OF SEIZURE-GENERATED GRANULE CELLS}

The accelerated NSC proliferation likewise is reflected by a marked increase in net neurogenesis (which is the number of new neurons that is actually generated). Similar to normal conditions, $\sim 75 \%-90 \%$ of all newly generated cells express markers characteristic of dentate granule cells 4 wk after labeling dividing cells with BrdU or retroviral reporter vectors (Parent et al. 1997; Jessberger et al. 2005, 2007a). Interestingly, seizure activity appears to accelerate the functional maturation and integration of adultborn granule cells, although the consequences of these effects on hippocampal network function are unknown (Overstreet-Wadiche et al. 2006). Some populations of seizure-generated granule cells in most temporal lobe epilepsy (TLE) models studied, however, show severe morphological abnormalities that might critically affect dentate connectivity. Basically, two features are altered in the course of seizureinduced neurogenesis: the formation of hilar basal dendrites and the ectopic migration of newborn granule cells into the polymorphic cell layer.

Granule cells that are born under normal conditions in the adult dentate gyrus are highly polarized neurons (Zhao et al. 2006; Toni et al. 2007). They have a single dendrite arising from the apical portion of the cell body branching in the distal GCL or proximal molecular layer (ML). Within the ML, excitatory synapses are formed onto granule cell dendrites by perforant path axons that connect neurons from the entorhinal cortex with dentate granule cells (van Praag et al. 2002; Schmidt-Hieber et al. 2004; Ge et al. 2006; Zhao et al. 2006). In striking contrast to cells born under normal conditions, a portion of seizure-generated granule cells extends an additional basal dendrite toward the hilus (Fig. 2) (Ribak et al. 2000; Dashtipour et al. 2003; Shapiro et al. 2005). During the immature, DCX-expressing stage of neuronal development, hilar basal dendrites form nonspiny immature synapses with mossy fiber axons (Shapiro and Ribak 2006). At later stages of granule cell development ( $>4$ wk postmitotic), hilar basal dendrites are covered with numerous spiny processes, among them mature mushroom spines (Jessberger et al. 2007a; Walter et al. 2007; Kron et al. 2010). Despite the abnormal integration that might result in the establishment of recurrent excitatory networks (Overstreet-Wadiche et al. 2006), granule cells that extend hilar basal dendrites become stably integrated into the dentate circuitry (Jessberger et al. 2007a; Walter et al. 2007; Kron et al. 2010), thus leading to lasting changes in dentate connectivity. The molecular mechanisms responsible for the extension of hilar basal dendrites are unknown but may involve an alteration in the glial scaffold and/or growth factor expression (Shapiro et al. 2005; Waterhouse et al. 2012). In contrast to hilar basal dendrites, sprouting of mossy fibers following seizures does not de- 


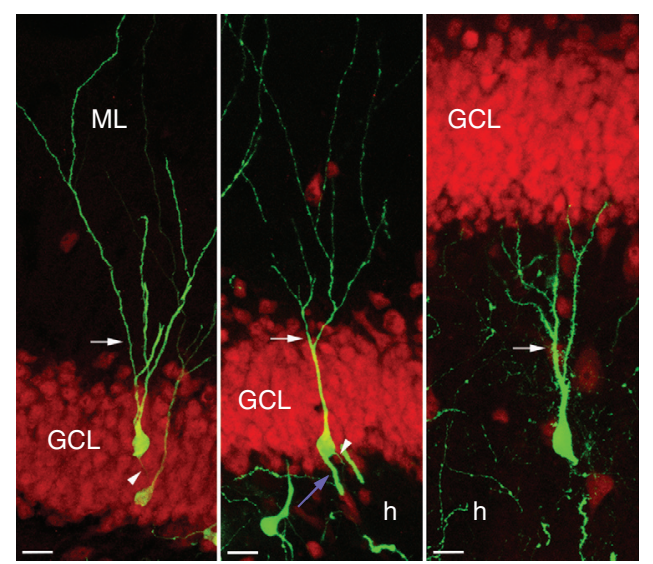

Figure 2. Neurogenesis following kainic acid (KA)induced seizures is largely aberrant. Retroviral labeling reveals the highly polarized morphology with a single apical dendrite (arrow) and an axon (arrowhead) extending from newborn granule cells that were born under normal conditions (left panel). KA-induced seizures lead to the formation of a basal dendrite (blue arrow) in addition to the apical dendritic (arrow) and axonal processes (arrowhead, middle panel). Another portion of seizure-generated granule cells ectopically migrates into the hilus (right panel). Surprisingly, some ectopic granule cells morphologically appear very normal despite the aberrant localization. Scale bar, $15 \mu \mathrm{m}$. GCL, granule cell layer; h, hilus; ML, molecular layer.

pend to a large extent on granule cells born after the epileptic insult (Parent et al. 1999), even though retroviral approaches showed that cells born after seizures also extend aberrant mossy fibers (Kron et al. 2010).

In addition to aberrant dendritic growth, $\mathrm{SE}$ alters the migration of adult-born neurons. Neuroblasts generated in the SVZ migrate more rapidly to the olfactory bulb, and a portion exits the migratory stream prematurely to enter nonolfactory forebrain regions (Parent et al. 2002). Few, if any, of the neuroblasts that reach the cortex appear to survive. In the dentate gyrus of adult rats, a substantial fraction of seizure-generated granule cells ectopically migrates into the hilus and toward the hilar/CA3 border, where they survive and integrate (Figs. 2 and 3) (Parent et al. 1997; Scharfman et al. 2000). Despite their abnormal localization, the intrinsic electrophysiological features of ectopic granule cells are remarkably similar to cells born under control conditions. However, ectopic granule cells burst in synchrony with CA3 pyramidal cells indicating aberrant integration into the dentate circuitry after SE (Scharfman et al. 2000). Remarkably, ectopic cells still receive normal synaptic input from the perforant path (Scharfman et al. 2002, 2003).

Why some seizure-generated granule cells migrate into the hilus remains unclear. Recent work suggests that $\mathrm{SE}$ induces abnormal chain migration of granule cell progenitors toward the hilus (Parent et al. 2006b), and this aberrant migratory behavior may be initiated by loss of reelin signaling (Gong et al. 2007; Teixeira et al. 2012). In addition, it has been shown recently that mTOR signaling is involved in the migratory behavior of newborn granule cells and that excessive (transgenic) activation of the mTOR pathways leads to aberrant migration of newborn cells in the hilus, phenocopying some of the effects of seizures on dentate neurogenesis (Pun et al. 2012). Future experiments are required to understand in more detail the cellular and molecular mechanisms that underlie cellautonomous and non-cell-autonomous effects leading to aberrant migration and dendritic integration of adult-born granule cells in models of mTLE.

\section{FUNCTIONAL RELEVANCE OF SEIZURE- INDUCED NEUROGENESIS}

Seizure-associated neurogenesis may play a role in two features of mTLE that are poorly understood from a mechanistic point of view. The first one is the progression from a brain insult to the clinical syndrome of epilepsy, a process called epileptogenesis (Dalby and Mody 2001; Magloczky and Freund 2005). What is the evidence that altered neurogenesis might be involved in epileptogenesis? Unquestionably, SE leads to heightened excitability and recurrent excitatory networks within the hippocampal circuitry. One reason for this might be the excitotoxic loss of inhibitory, GABAergic neurons, although debate is ongoing regarding the relevance of cell death or interneuronal disconnection in the establishment of an epileptic circuitry (Bernard 

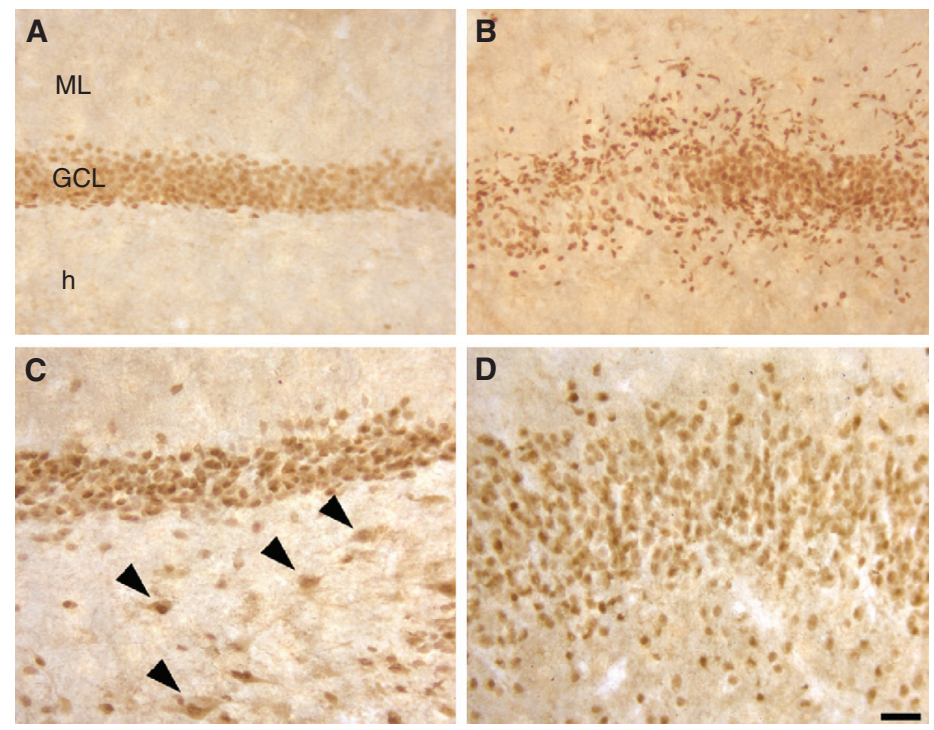

Figure 3. Ectopic granule cells in experimental and human mesial temporal lobe epilepsy (mTLE). (Top panels) Proxl immunoreactivity in adult rat dentate gyrus $35 \mathrm{~d}$ after saline treatment $(A)$ or pilocarpine-induced status epilepticus (SE) (B) shows many ectopic granule neurons in the epileptic rat $(B)$ but not in the control $(A)$. (Bottom panels) NeuN immunoreactivity in control human (C; temporal lobe tumor) and human mTLE $(D)$ dentate gyrus shows granule cell layer (GCL) dispersion and ectopic granule-like neurons in the hilus (h) and molecular layer $(\mathrm{ML})$ only in the patient with mTLE who had mesial temporal sclerosis $(D)$. Arrowheads $(C)$ point to larger, NeuN-immunoreactive hilar neurons in the control tissue that are not seen in the mTLE subject $(D)$ caused by hilar cell loss, or in either rat $(A, B)$ because Proxl is expressed specifically in dentate granule cells. Scale bars, $100 \mu \mathrm{m}(A, B) ; 50 \mu \mathrm{m}(C, D)$.

et al. 1998; Dalby and Mody 2001; Sloviter et al. 2003; Ratzliff et al. 2004). Seizure-generated granule cells show two features that might indicate an epileptogenic role. Seizure-generated granule cells with hilar basal dendrites receive excitatory input from mossy fibers and could, thus, form a recurrent excitatory circuit (Fig. 4) (Shapiro and Ribak 2006). Similarly, ectopic granule cells appear to be abnormally synchronized with spontaneous, rhythmic bursts of CA3 pyramidal neurons (Scharfman et al. 2000). Compatible with those data is the finding that the reduction of seizure-generated neurons impairs epileptogenesis and reduces the frequency of spontaneous recurrent seizures (Jung et al. 2004, 2006). Abnormal network formation that results from altered neurogenesis after brain injury may also support seizure propagation or adversely influence seizure termination mechanisms. Even stronger support comes from the recent finding that aberrant neurogenesis is sufficient to induce spontaneous seizures in an otherwise intact animal (Pun et al. 2012). Strikingly, as few as $9 \%$ of "wrongly" connected newborn granule cells, induced by mTOR activation (see above), are sufficient to induce spontaneous seizures (Pun et al. 2012). These data strongly suggest a proepileptogenic role for new neurons. However, there is also evidence that seizure-induced neurogenesis may play a compensatory role in SE models using electrical stimulation to induce SE (Jakubs et al. 2006). In this model, seizure-generated granule cells have less excitatory but increased inhibitory input resulting in overall decreased excitability compared with newborn cells generated in running rats (Jakubs et al. 2006). Given this finding, the heightened excitability within the epileptic hippocampal circuitry might be compensated through more inhibited newborn granule cells. This hypothesis is supported by other studies that showed no detrimental or rather positive 

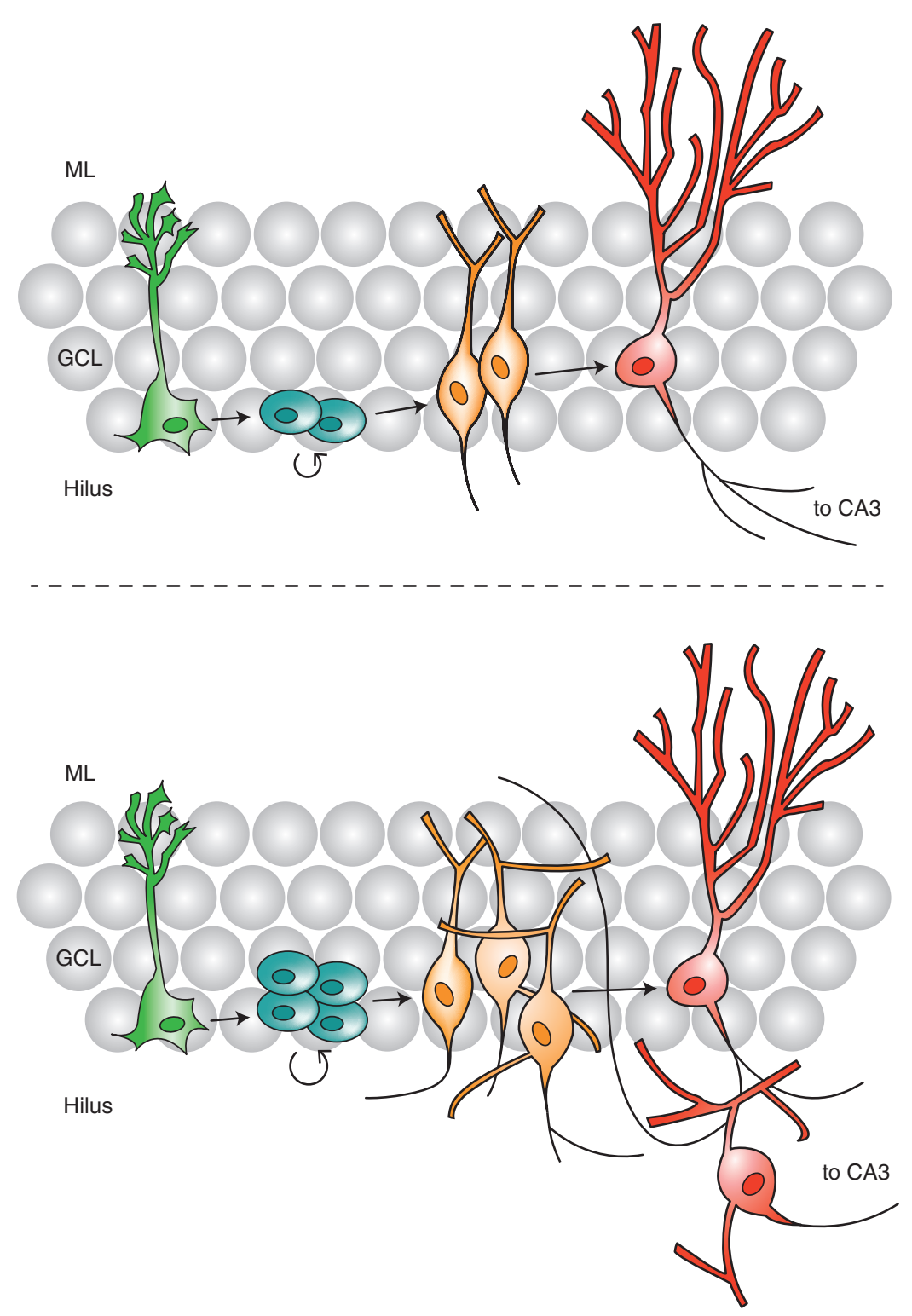

Figure 4. Aberrant integration of adult-born neurons after SE alters dentate gyrus circuitry. Top panel shows a schematic of the normal dentate gyrus with radial glia-like neural stem cells (NSCs) (green) that generate more proliferative type- 2 cells (blue) that give rise to immature neurons that extend dendrites toward molecular layer (ML) and their axons (mossy fibers) toward the hilus (orange). Mature newborn neurons functionally integrate with their dendrites in the ML and send their axons to area CA3 and hilar regions (red). In experimental mesial temporal lobe epilepsy (mTLE) (bottom panel), status epilepticus (SE) increases neurogenesis and also alters the integration of differentiating neurons. Proliferation of radial glia-like cells (green) and also type-2 cells is strongly enhanced (blue). Cells born after SE extend aberrant dendrites into the hilar region (orange). Aberrant dendrites remain also on fully mature newborn granule cells (red) that may be implicated in disturbing dentate connectivity. Furthermore, mossy fiber sprouting occurs from seizure-generated (red) but also preexisting mature granule cells (not shown in this scheme). In addition to aberrant neurite extension and integration, some seizure-generated neurons migrate ectopically to reside in hilus (figure prepared by Simon Braun, University of Zurich). 
effects of SE-induced neurogenesis on hippocampal network function (Raedt et al. 2007; Pekcec et al. 2011).

Without a doubt, the question of whether seizure-generated granule cells are part of the disease or an attempt of the injured brain to repair itself is far from conclusively answered. Given the heterogeneous nature of DGCs generated after SE in the adult hippocampus (Murphy et al. 2011), populations of normally and aberrantly integrated adult-born DGCs likely arise after SE that may exert opposing influences on excitability. However, future studies that reproduce consequences of seizure activity on adult neurogenesis in otherwise intact animals likely will help answer this critical question.

Another consequence of mTLE is the common occurrence of cognitive dysfunction that often leads to substantial morbidity (Helmstaedter et al. 2003; Elger et al. 2004). There is growing evidence that adult neurogenesis is involved in certain forms of hippocampus-dependent learning and memory under normal conditions (Shors et al. 2001, 2002; Santarelli et al. 2003; Snyder et al. 2005; Meshi et al. 2006; Saxe et al. 2006; Winocur et al. 2006). Seizure-generated neurons might contribute to cognitive impairment associated with TLE in three respects. First, the "normal" function of adult-generated neurons that might depend on specific plasticity of immature neurons (Schmidt-Hieber et al. 2004) might be disrupted because of an altered integration pattern (Overstreet-Wadiche et al. 2006; Jessberger et al. 2007b). Second, the well-documented aberrant integration (hilar basal dendrites and ectopic granule cells) in most rodent models of mTLE could critically interfere with synaptic transmission and information processing (Fig. 4). A third potential influence is that chronic suppression of neurogenesis in the epileptic brain (Hattiangady et al. 2004) could interfere with hippocampus-dependent learning and memory (Clelland et al. 2009; Deng et al. 2010; Sahay et al. 2011). As is the case for adult neurogenesis under normal conditions, however, the functional role of seizure-generated neurons in epileptogenesis or cognitive impairment will only be satisfyingly answered if ablation strategies with a higher spe- cificity and selectivity than the ones that are currently available are developed.

\section{SUMMARY}

The finding that adult neurogenesis is altered dramatically during epileptogenesis challenges the conceptual understanding of the cause and consequences of mTLE. Most rodent models of mTLE are associated with severe alterations in morphology and connectivity of adult-born neurons, such as the extension of hilar basal dendrites and the ectopic migration into the hilus of granule cell progenitors. To date, however, the role new neurons actually play in the epileptic disease process remains unclear. Simply put, are they good or bad? In the end, both descriptions may prove valid in that some aspects of seizure-induced neurogenesis might be beneficial and others harmful for the epileptic brain. In any case, the characterization and identification of cellular and molecular mechanisms underlying seizure-induced neurogenesis will bring us one step further toward understanding ongoing plasticity in the adult brain. Without a doubt, seizure-induced neurogenesis represents a promising target for intervention in the treatment of human epilepsy and its comorbidities.

\section{REFERENCES}

Banerjee SB, Rajendran R, Dias BG, Ladiwala U, Tole S, Vaidya VA. 2005. Recruitment of the Sonic hedgehog signalling cascade in electroconvulsive seizure-mediated regulation of adult rat hippocampal neurogenesis. Eur J Neurosci 22: 1570-1580.

Bengzon J, Kokaia Z, Elmér E, Nanobashvili A, Kokaia M, Lindvall O. 1997. Apoptosis and proliferation of dentate gyrus neurons after single and intermittent limbic seizures. Proc Natl Acad Sci 94: 10432-10437.

Bernard C, Esclapez M, Hirsch JC, Ben-Ari Y. 1998. Interneurones are not so dormant in temporal lobe epilepsy: A critical reappraisal of the dormant basket cell hypothesis. Epilepsy Res 32: 93-103.

Blumcke I, Beck H, Lie AA, Wiestler OD. 1999. Molecular neuropathology of human mesial temporal lobe epilepsy. Epilepsy Res 36: 205-223.

Blumcke I, Coras R, Miyata H, Ozkara C. 2012. Defining clinico-neuropathological subtypes of mesial temporal lobe epilepsy with hippocampal sclerosis. Brain Pathol 22: $402-411$. 
Blume WT. 2006. The progression of epilepsy. Epilepsia 47: 71-78.

Bonde S, Ekdahl CT, Lindvall O. 2006. Long-term neuronal replacement in adult rat hippocampus after status epilepticus despite chronic inflammation. Eur J Neurosci 23: 965-974.

Buckmaster PS. 2004. Laboratory animal models of temporal lobe epilepsy. Comp Med 54: 473-485.

Clelland CD, Choi M, Romberg C, Clemenson GD Jr, Fragniere A, Tyers P, Jessberger S, Saksida LM, Barker RA, Gage FH, et al. 2009. A functional role for adult hippocampal neurogenesis in spatial pattern separation. Science 325: 210-213.

Dalby NO, Mody I. 2001. The process of epileptogenesis: A pathophysiological approach. Curr Opin Neurol 14: 187192.

Dashtipour K, Wong AM, Obenaus A, Spigelman I, Ribak CE. 2003. Temporal profile of hilar basal dendrite formation on dentate granule cells after status epilepticus. Epilepsy Res 54: 141-151.

Deisseroth K, Singla S, Toda H, Monje M, Palmer TD, Malenka RC. 2004. Excitation-neurogenesis coupling in adult neural stem/progenitor cells. Neuron 42: 535-552.

Deng W, Aimone JB, Gage FH. 2010. New neurons and new memories: How does adult hippocampal neurogenesis affect learning and memory? Nat Rev Neurosci 11: 339350.

Ekdahl CT, Claasen JH, Bonde S, Kokaia Z, Lindvall O. 2003. Inflammation is detrimental for neurogenesis in adult brain. Proc Natl Acad Sci 100: 13632-13637.

Elger CE, Helmstaedter C, Kurthen M. 2004. Chronic epilepsy and cognition. Lancet Neurol 3: 663-672.

Elliott RC, Lowenstein DH. 2004. Gene expression profiling of seizure disorders. Neurochem Res 29: 1083-1092.

Faigle R, Song H. 2013. Signaling mechanisms regulating adult neural stem cells and neurogenesis. Biochim Biophys Acta 1830: 2435-2448.

Gall CM. 1993. Seizure-induced changes in neurotrophin expression: Implications for epilepsy. Exp Neurol 124: $150-166$.

Ge S, Goh EL, Sailor KA, Kitabatake Y, Ming GL, Song H. 2006. GABA regulates synaptic integration of newly generated neurons in the adult brain. Nature 439: 589-593.

Gong C, Wang TW, Huang HS, Parent JM. 2007. Reelin regulates neuronal progenitor migration in intact and epileptic hippocampus. J Neurosci 27: 1803-1811.

Gould E, Cameron HA, McEwen BS. 1994. Blockade of NMDA receptors increases cell death and birth in the developing rat dentate gyrus. J Comp Neurol 340: 551565.

Gray WP, Sundstrom LE. 1998. Kainic acid increases the proliferation of granule cell progenitors in the dentate gyrus of the adult rat. Brain Res 790: 52-59.

Hattiangady B, Rao MS, Shetty AK. 2004. Chronic temporal lobe epilepsy is associated with severely declined dentate neurogenesis in the adult hippocampus. Neurobiol Dis 17: $473-490$.

Helmstaedter C. 2002. Effects of chronic epilepsy on declarative memory systems. Prog Brain Res 135: 439-453.
Helmstaedter C, Kurthen M, Lux S, Reuber M, Elger CE. 2003. Chronic epilepsy and cognition: A longitudinal study in temporal lobe epilepsy. Ann Neurol 54: 425-432.

Huang Y, Doherty JJ, Dingledine R. 2002. Altered histone acetylation at glutamate receptor 2 and brain-derived neurotrophic factor genes is an early event triggered by status epilepticus. J Neurosci 22: 8422-8428.

Huttmann K, Sadgrove M, Wallraff A, Hinterkeuser S, Kirchhoff F, Steinhauser C, Gray WP. 2003. Seizures preferentially stimulate proliferation of radial glia-like astrocytes in the adult dentate gyrus: Functional and immunocytochemical analysis. Eur J Neurosci 18: 2769-2778.

Isackson PJ, Huntsman MM, Murray KD, Gall CM. 1991. BDNF mRNA expression is increased in adult rat forebrain after limbic seizures: Temporal patterns of induction distinct from NGF. Neuron 6: 937-948.

Jakubs K, Nanobashvili A, Bonde S, Ekdahl CT, Kokaia Z, Kokaia M, Lindvall O. 2006. Environment matters: Synaptic properties of neurons born in the epileptic adult brain develop to reduce excitability. Neuron 52: 10471059.

Jang MH, Bonaguidi MA, Kitabatake Y, Sun J, Song J, Kang E, Jun H, Zhong C, Su Y, Guo JU, et al. 2013. Secreted frizzled-related protein 3 regulates activity-dependent adult hippocampal neurogenesis. Cell Stem Cell 12: 215-223.

Jessberger S, Romer B, Babu H, Kempermann G. 2005. Seizures induce proliferation and dispersion of doublecortin-positive hippocampal progenitor cells. Exp Neurol 196: $342-351$.

Jessberger S, Zhao C, Toni N, Clemenson GD Jr, Li Y, Gage FH. 2007a. Seizure-associated, aberrant neurogenesis in adult rats characterized with retrovirus-mediated cell labeling. J Neurosci 27: 9400-9407.

Jessberger S, Nakashima K, Clemenson GD Jr, Mejia E, Mathews E, Ure K, Ogawa S, Sinton CM, Gage FH, Hsieh J. 2007b. Epigenetic modulation of seizure-induced neurogenesis and cognitive decline. J Neurosci 27: 59675975.

Jung KH, Chu K, Kim M, Jeong SW, Song YM, Lee ST, Kim JY, Lee SK, Roh JK. 2004. Continuous cytosine-b-D-arabinofuranoside infusion reduces ectopic granule cells in adult rat hippocampus with attenuation of spontaneous recurrent seizures following pilocarpine-induced status epilepticus. Eur J Neurosci 19: 3219-3226.

Jung KH, Chu K, Lee ST, Kim J, Sinn DI, Kim JM, Park DK, Lee JJ, Kim SU, Kim M, et al. 2006. Cyclooxygenase-2 inhibitor, celecoxib, inhibits the altered hippocampal neurogenesis with attenuation of spontaneous recurrent seizures following pilocarpine-induced status epilepticus. Neurobiol Dis 23: 237-246.

Kralic JE, Ledergerber DA, Fritschy JM. 2005. Disruption of the neurogenic potential of the dentate gyrus in a mouse model of temporal lobe epilepsy with focal seizures. Eur J Neurosci 22: 1916-1927.

Kron MM, Zhang H, Parent JM. 2010. The developmental stage of dentate granule cells dictates their contribution to seizure-induced plasticity. J Neurosci 30: 2051-2059.

Lugert S, Basak O, Knuckles P, Haussler U, Fabel K, Gotz M, Haas CA, Kempermann G, Taylor V, Giachino C. 2010. Quiescent and active hippocampal neural stem cells with distinct morphologies respond selectively to physiologi- 
cal and pathological stimuli and aging. Cell Stem Cell 6: 445-456.

Magloczky Z, Freund TF. 2005. Impaired and repaired inhibitory circuits in the epileptic human hippocampus. Trends Neurosci 28: 334-340.

Meshi D, Drew MR, Saxe M, Ansorge MS, David D, Santarelli L, Malapani C, Moore H, Hen R. 2006. Hippocampal neurogenesis is not required for behavioral effects of environmental enrichment. Nat Neurosci 9: 729-731.

Mohapel P, Ekdahl CT, Lindvall O. 2004. Status epilepticus severity influences the long-term outcome of neurogenesis in the adult dentate gyrus. Neurobiol Dis 15: 196205.

Murphy BL, Pun RY, Yin H, Faulkner CR, Loepke AW, Danzer SC. 2011. Heterogeneous integration of adultgenerated granule cells into the epileptic brain. J Neurosci 31: 105-117.

Newton SS, Collier EF, Hunsberger J, Adams D, Terwilliger R, Selvanayagam E, Duman RS. 2003. Gene profile of electroconvulsive seizures: Induction of neurotrophic and angiogenic factors. J Neurosci 23: 10841-10851.

Overstreet-Wadiche LS, Bromberg DA, Bensen AL, Westbrook GL. 2006. Seizures accelerate functional integration of adult-generated granule cells. J Neurosci 26: 4095-4103.

Parent JM, Yu TW, Leibowitz RT, Geschwind DH, Sloviter RS, Lowenstein DH. 1997. Dentate granule cell neurogenesis is increased by seizures and contributes to aberrant network reorganization in the adult rat hippocampus. J Neurosci 17: 3727-3738.

Parent JM, Tada E, Fike JR, Lowenstein DH. 1999. Inhibition of dentate granule cell neurogenesis with brain irradiation does not prevent seizure-induced mossy fiber synaptic reorganization in the rat. J Neurosci 19: 4508-4519.

Parent JM, Valentin VV, Lowenstein DH. 2002. Prolonged seizures increase proliferating neuroblasts in the adult rat subventricular zone-olfactory bulb pathway. J Neurosci 22: 3174-3188.

Parent JM, von dem Bussche N, Lowenstein DH. 2006a. Prolonged seizures recruit caudal subventricular zone glial progenitors into the injured hippocampus. Hippocampus 16: 321-328.

Parent JM, Elliott RC, Pleasure SJ, Barbaro NM, Lowenstein DH. 2006b. Aberrant seizure-induced neurogenesis in experimental temporal lobe epilepsy. Ann Neurol 59: 81-91.

Pekcec A, Lupke M, Baumann R, Seifert H, Potschka H. 2011. Modulation of neurogenesis by targeted hippocampal irradiation fails to affect kindling progression. Hippocampus 21: 866-876.

Pun RY, Rolle IJ, Lasarge CL, Hosford BE, Rosen JM, Uhl JD, Schmeltzer SN, Faulkner C, Bronson SL, Murphy BL, et al. 2012. Excessive activation of mTOR in postnatally generated granule cells is sufficient to cause epilepsy. Neuron 75: 1022-1034.

Raedt R, Boon P, Persson A, Alborn AM, Boterberg T, Van Dycke A, Linder B, De Smedt T, Wadman WJ, Ben-Menachem E, et al. 2007. Radiation of the rat brain suppresses seizure-induced neurogenesis and transiently enhances excitability during kindling acquisition. Epilepsia 48: 1952-1963.
Ratzliff AH, Howard AL, Santhakumar V, Osapay I, Soltesz I. 2004. Rapid deletion of mossy cells does not result in a hyperexcitable dentate gyrus: Implications for epileptogenesis. J Neurosci 24: 2259-2269.

Ribak CE, Tran PH, Spigelman I, Okazaki MM, Nadler JV. 2000. Status epilepticus-induced hilar basal dendrites on rodent granule cells contribute to recurrent excitatory circuitry. J Comp Neurol 428: 240-253.

Sahay A, Scobie KN, Hill AS, O'Carroll CM, Kheirbek MA, Burghardt NS, Fenton AA, Dranovsky A, Hen R. 2011. Increasing adult hippocampal neurogenesis is sufficient to improve pattern separation. Nature 472: 466-470.

Santarelli L, Saxe M, Gross C, Surget A, Battaglia F, Dulawa S, Weisstaub N, Lee J, Duman R, Arancio O, et al. 2003. Requirement of hippocampal neurogenesis for the behavioral effects of antidepressants. Science 301: 805-809.

Saxe MD, Battaglia F, Wang JW, Malleret G, David DJ, Monckton JE, Garcia AD, Sofroniew MV, Kandel ER, Santarelli L, et al. 2006. Ablation of hippocampal neurogenesis impairs contextual fear conditioning and synaptic plasticity in the dentate gyrus. Proc Natl Acad Sci 103: 17501-17506.

Scharfman HE, Goodman JH, Sollas AL. 2000. Granule-like neurons at the hilar/CA3 border after status epilepticus and their synchrony with area CA3 pyramidal cells: Functional implications of seizure-induced neurogenesis. $J$ Neurosci 20: 6144-6158.

Scharfman HE, Sollas AL, Goodman JH. 2002. Spontaneous recurrent seizures after pilocarpine-induced status epilepticus activate calbindin-immunoreactive hilar cells of the rat dentate gyrus. Neuroscience 111: 71-81.

Scharfman HE, Sollas AE, Berger RE, Goodman JH, Pierce JP. 2003. Perforant path activation of ectopic granule cells that are born after pilocarpine-induced seizures. Neuroscience 121: 1017-1029.

Schmidt-Hieber C, Jonas P, Bischofberger J. 2004. Enhanced synaptic plasticity in newly generated granule cells of the adult hippocampus. Nature 429: 184-187.

Scott BW, Wang S, Burnham WM, De Boni U, Wojtowicz JM. 1998. Kindling-induced neurogenesis in the dentate gyrus of the rat. Neurosci Lett 248: 73-76.

Shapiro LA, Ribak CE. 2006. Newly born dentate granule neurons after pilocarpine-induced epilepsy have hilar basal dendrites with immature synapses. Epilepsy Res 69: $53-66$.

Shapiro LA, Korn MJ, Ribak CE. 2005. Newly generated dentate granule cells from epileptic rats exhibit elongated hilar basal dendrites that align along GFAP-immunolabeled processes. Neuroscience 136: 823-831.

Shors TJ, Miesegaes G, Beylin A, Zhao M, Rydel T, Gould E. 2001. Neurogenesis in the adult is involved in the formation of trace memories. Nature 410: 372-376.

Shors TJ, Townsend DA, Zhao M, Kozorovitskiy Y, Gould E. 2002. Neurogenesis may relate to some but not all types of hippocampal-dependent learning. Hippocampus 12: $578-584$.

Sibbe M, Haussler U, Dieni S, Althof D, Haas CA, Frotscher M. 2012. Experimental epilepsy affects Notch1 signalling and the stem cell pool in the dentate gyrus. Eur J Neurosci 36: $3643-3652$. 


\section{S. Jessberger and J.M. Parent}

Sloviter RS, Zappone CA, Harvey BD, Bumanglag AV, Bender RA, Frotscher M. 2003. "Dormant basket cell” hypothesis revisited: Relative vulnerabilities of dentate gyrus mossy cells and inhibitory interneurons after hippocampal status epilepticus in the rat. J Comp Neurol 459: 44-76.

Snyder JS, Hong NS, McDonald RJ, Wojtowicz JM. 2005. A role for adult neurogenesis in spatial long-term memory. Neuroscience 130: 843-852.

Song J, Zhong C, Bonaguidi MA, Sun GJ, Hsu D, Gu Y, Meletis K, Huang ZJ, Ge S, Enikolopov G, et al. 2012. Neuronal circuitry mechanism regulating adult quiescent neural stem-cell fate decision. Nature 489: 150-154.

Teixeira CM, Kron MM, Masachs N, Zhang H, Lagace DC, Martinez A, Reillo I, Duan X, Bosch C, Pujadas L, et al. 2012. Cell-autonomous inactivation of the reelin pathway impairs adult neurogenesis in the hippocampus. $J$ Neurosci 32: 12051-12065.

Toni N, Teng EM, Bushong EA, Aimone JB, Zhao C, Consiglio A, van Praag H, Martone ME, Ellisman MH, Gage FH. 2007. Synapse formation on neurons born in the adult hippocampus. Nat Neurosci 10: 727-734.

Tozuka Y, Fukuda S, Namba T, Seki T, Hisatsune T. 2005. GABAergic excitation promotes neuronal differentiation in adult hippocampal progenitor cells. Neuron 47: 803815 . van Praag H, Schinder AF, Christie BR, Toni N, Palmer TD, Gage FH. 2002. Functional neurogenesis in the adult hippocampus. Nature 415: 1030-1034.

von Lehe M, Lutz M, Kral T, Schramm J, Elger CE, Clusmann H. 2006. Correlation of health-related quality of life after surgery for mesial temporal lobe epilepsy with two seizure outcome scales. Epilepsy Behav 9: 73-82.

Walter C, Murphy BL, Pun RY, Spieles-Engemann AL, Danzer SC. 2007. Pilocarpine-induced seizures cause selective time-dependent changes to adult-generated hippocampal dentate granule cells. J Neurosci 27: 75417552.

Waterhouse EG, An JJ, Orefice LL, Baydyuk M, Liao GY, Zheng K, Lu B, Xu B. 2012. BDNF promotes differentiation and maturation of adult-born neurons through GABAergic transmission. J Neurosci 32: 14318-14330.

Winocur G, Wojtowicz JM, Sekeres M, Snyder JS, Wang S. 2006. Inhibition of neurogenesis interferes with hippocampus-dependent memory function. Hippocampus 16: 296-304.

Zhao C, Teng EM, Summers RG Jr, Ming GL, Gage FH. 2006. Distinct morphological stages of dentate granule neuron maturation in the adult mouse hippocampus. $J$ Neurosci 26: 3-11. 


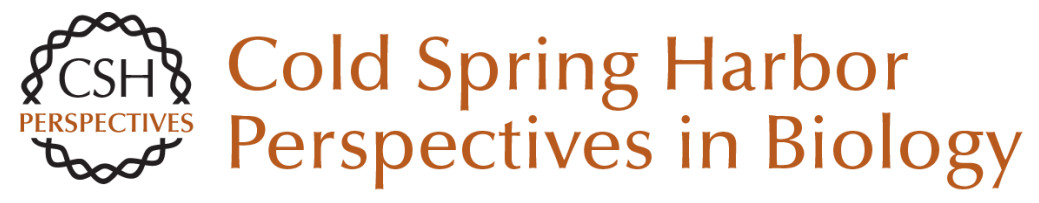

\section{Epilepsy and Adult Neurogenesis}

Sebastian Jessberger and Jack M. Parent

Cold Spring Harb Perspect Biol 2015; doi: 10.1101/cshperspect.a020677 originally published online November 9, 2015

\section{Subject Collection Neurogenesis}

Adult Neurogenesis and Psychiatric Disorders Eunchai Kang, Zhexing Wen, Hongjun Song, et al.

Neuronal Circuitry Mechanisms Regulating Adult Mammalian Neurogenesis Juan Song, Reid H.J. Olsen, Jiaqi Sun, et al.

Neurogenesis in the Developing and Adult Brain

--Similarities and Key Differences

Magdalena Götz, Masato Nakafuku and David Petrik

Genetics and Epigenetics in Adult Neurogenesis Jenny Hsieh and Xinyu Zhao

The Adult Ventricular-Subventricular Zone (V-SVZ) and Olfactory Bulb (OB) Neurogenesis Daniel A. Lim and Arturo Alvarez-Buylla

Diversity of Neural Precursors in the Adult Mammalian Brain Michael A. Bonaguidi, Ryan P. Stadel, Daniel A. Berg, et al.

Detection and Phenotypic Characterization of Adult Neurogenesis $H$. Georg Kuhn, Amelia J. Eisch, Kirsty Spalding, et al.

Maturation and Functional Integration of New Granule Cells into the Adult Hippocampus Nicolas Toni and Alejandro F. Schinder
Adult Olfactory Bulb Neurogenesis

Pierre-Marie Lledo and Matt Valley

Adult Neurogenesis in Fish Julia Ganz and Michael Brand

In Vitro Models for Neurogenesis Hassan Azari and Brent A. Reynolds

Engineering of Adult Neurogenesis and Gliogenesis

Benedikt Berninger and Sebastian Jessberger

Computational Modeling of Adult Neurogenesis James B. Aimone

Control of Adult Neurogenesis by Short-Range Morphogenic-Signaling Molecules Youngshik Choe, Samuel J. Pleasure and Helena Mira

Adult Neurogenesis: An Evolutionary Perspective Gerd Kempermann

Epilepsy and Adult Neurogenesis

Sebastian Jessberger and Jack M. Parent

For additional articles in this collection, see http://cshperspectives.cshlp.org/cgi/collection/

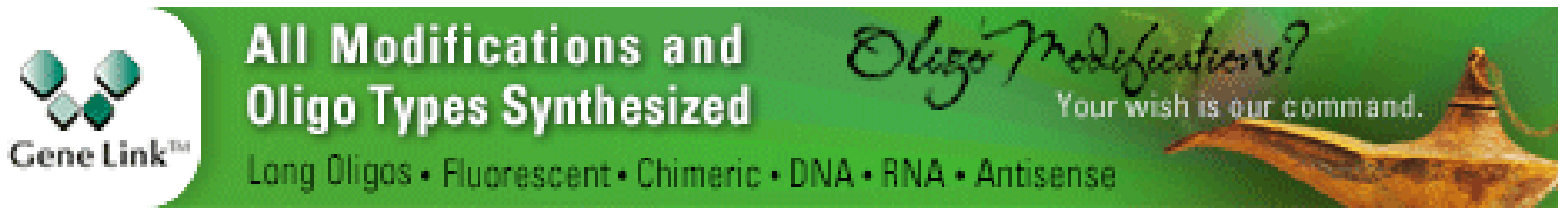


For additional articles in this collection, see http://cshperspectives.cshlp.org/cgi/collection/

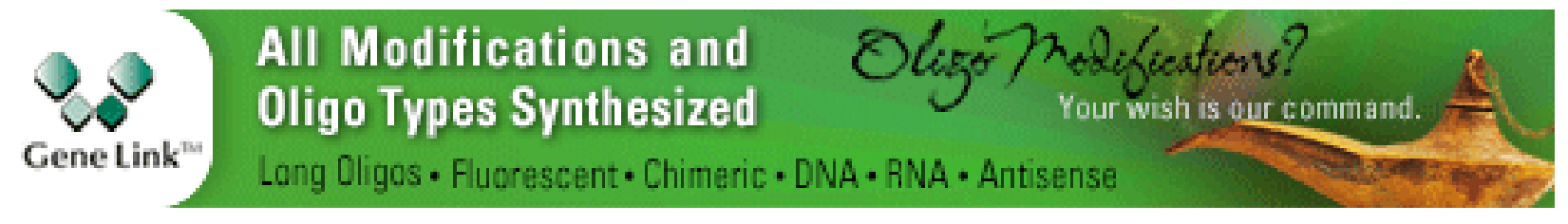

Copyright @ 2015 Cold Spring Harbor Laboratory Press; all rights reserved 